\title{
Views on a "Good Death": End-of-Life Preferences and Their Association With Socio-Demographic Characteristics in a Representative Sample of Older Adults in Switzerland
}

OMEGA_Journal of Death and Dying

(C) The Author(s) 2020

Article reuse guidelines: sagepub.com/journals-permissions DOI: | 0.1 I 77/003022282094507|

journals.sagepub.com/home/ome

@SAGE

\section{Carmen Borrat-Besson' (D, Sarah Vilpert ${ }^{1,2}$, Gian Domenico Borasio ${ }^{3,4}$, and Jürgen Maurer ${ }^{5}$}

\footnotetext{
Abstract

The current study explores the end-of-life (EOL) preferences of a national representative sample of adults aged 55 and older in Switzerland and shows how these preferences vary by respondents' sociodemographic characteristics and the linguistic region in which they live. Many of the presented EOL attributes are considered as (very) important by a large majority of the older population in Switzerland with significant variations across sociodemographic groups. Specifically, gender is related

'Swiss Centre of Expertise in the Social Sciences (FORS), University of Lausanne, Switzerland

${ }^{2}$ Faculty of Biology and Medicine, University of Lausanne, Switzerland

${ }^{3}$ Palliative and Supportive Care Service, Lausanne University Hospital, Switzerland

${ }^{4}$ University of Lausanne, Switzerland

${ }^{5}$ Department of Economics, Faculty of Business and Economics (HEC), University of Lausanne, Switzerland Corresponding Author:

Carmen Borrat-Besson, Swiss Centre of Expertise in the Social Sciences (FORS), c/o University of Lausanne, Geopolis, I0I5 Lausanne, Switzerland.

Email: carmen.borrat-besson@fors.unil.ch
} 
to psychosocial aspects of EOL, age to the importance attached to avoiding being a burden on the society, and education levels to preferences regarding overtreatment and advance care planning. The results highlight the importance of a personalized, holistic and interdisciplinary approach to EOL and EOL care, since social, psychological, organizational and physical aspects of EOL are rated as (very) important with significant differences in EOL preferences across sociodemographic groups.

\section{Keywords}

attitude, population, survey, general public

Advances in modern medicine have had a significant impact on our attitudes toward end of life (EOL) and death (Castra, 2003). Besides increasing life expectancy, modern medicine also had a profound impact on the pattern of causes of death in the population, with sudden deaths becoming much less frequent. Thanks to sanitary revolution and technological progress in medicine, people nowadays mostly die at more advanced ages, often following a period of illness and prolonged polymorbidity. Consequently, EOL is, in most cases, a period of the life cycle that can be subject to some planning.

Yet, while recent medical achievements have indeed succeeded in prolonging life, they have also raised new questions about which interventions are still to be considered reasonable at the EOL and new related concerns of patients, including fears of overtreatment, of a potentially long, painful or undignified period of dying, and of dying in a medical setting such as a hospital or a nursing home. These concerns have led to a new debate on the quality of the dying process, with the aim of not just adding months to people's life, but of ensuring the best possible quality of life at the EOL, by accompanying people in their own experience of death, taking into account their EOL preferences and goals.

Echoing this paradigm shift, several recent studies have examined the meaning of a "good death" for dying patients, their relatives and the involved healthcare providers (Borreani \& Miccinesi, 2008; Meier et al., 2016). However, most existing studies have been conducted with hospitalized patients (Heyland et al., 2006; Hirai et al., 2006; Payne et al., 1996; Pierson et al., 2002; Singer et al., 1999; Steinhauser et al., 2000; Vig et al., 2002; Vig \& Pearlman, 2004), accompanying family members (Heyland et al., 2006; Steinhauser et al., 2000) and healthcare providers (Payne et al., 1996; Steinhauser et al., 2000). Only few studies have looked at EOL preferences in the general population (Leichtentritt \& Rettig, 2000; Miyashita et al., 2007; Rietjens et al., 2006; Tong et al., 2003).

Population-based studies exploring EOL preferences usually focus on advance care planning behaviors (i.e. writing advance directives, appointing a 
power of attorney and discussing EOL preferences) (Carr, 2012; Carr \& Khodyakov, 2007; Vilpert et al., 2018). However, they rarely focus on EOL preferences as such, despite increasing interest upon the general population, and especially older people, to reflect on their EOL preferences in the context of increasing opportunities for advance care planning. Thus, the first aim of our study is to examine the EOL preferences in a nationally representative sample of adults aged 55 and over in Switzerland. The second aim is to explore the potential diversity of EOL preferences across different socio-demographic groups as existing studies indicate that EOL preferences are likely to vary by gender (Arber et al., 2008; Bookwala et al., 2001; Rietjens et al., 2006) education (Rietjens et al., 2006), age, geographical areas (Rainsford et al., 2018; Wilson et al., 2009) and culture (Hirai et al., 2006; Leichtentritt \& Rettig, 2000; Rietjens et al., 2006).

\section{Methods}

\section{Sample}

A paper-and-pencil questionnaire about EOL issues was distributed to the Swiss respondents of the sixth wave of the Survey of Health, Ageing and Retirement in Europe (SHARE) conducted in 2015 (Börsch-Supan et al., 2013; Malter \& Börsch-Supan, 2017). SHARE is a longitudinal, interdisciplinary and crossnational survey that collects demographic, health, social and economic data based on a nationally representative sample of the population aged 50 and over in different European countries and Israel. Interviews are conducted face-to-face with the target respondents and consenting partners. Swiss respondents completed the EOL questionnaire at the end of the regular face-to-face interview. Data from the paper-and-pencil questionnaire were linked to the data of the face-to-face interview. Since the Swiss SHARE sample was not refreshed since 2011, its target respondents were all aged 55 and older at the time of the survey. Partners younger than 55 years old were, therefore, excluded from the analyses.

\section{Measures}

The EOL questionnaire included a list of 23 EOL attributes (see Supplementary Annex 1) derived from the scientific literature on individuals' views of what may constitute a "good death" (Meier et al., 2016; Steinhauser et al., 2000). The original English items were translated in German, French and Italian by professional translators and reviewed by researchers fluent in the 3 languages.

Respondents were asked to rate the importance of each of the $23 \mathrm{EOL}$ attributes on a 4 -point Likert scale $(1=$ not important; $2=$ not so important; 
$3=$ important; $4=$ very important) when considering the last six months of their life.

Respondents' socio-demographic characteristics considered in this paper were gender, age (55-64 years, 65-74 years, 75+ years), education (ISCED levels $1-2,3-4$, and 5-6) and the linguistic region based on questionnaire language (German, French, Italian). Education levels were measured according to the ISCED1997 classification and grouped in three categories: elementary and lower secondary education (referred below as "elementary"), upper- and postsecondary education (referred below as "secondary"), tertiary education (referred below as "tertiary"). The logistic regression models were further controlled for partnership status (live or not with a partner), number of children (none, 1 child, 2 children, $>=3$ children), urbanity of their residence (rural, urban), subjective financial situation (makes ends meet with great/some difficulties or fairly easily, makes ends meet easily), frequency of prayer (less than once a week or never, at least once a week), subjective health status (poor/fair/good, very good/excellent) and the presence of depressive symptoms as assessed by the EURO-D scale (Prince et al., 1999).

\section{Statistical Analysis}

Descriptive statistics (Table 1) and estimated proportions (Figure 1) were weighted using calibrated cross-sectional weights provided by SHARE (Malter \& Börsch-Supan, 2017) to make them representative of the target

Table I. Sociodemographic Characteristics of the Descriptive Sample.

\begin{tabular}{lccc}
\hline & & \multicolumn{2}{c}{ Weighted } \\
\cline { 3 - 4 } Characteristics & $\begin{array}{c}\text { Unweigthed N } \\
\text { (Total = 2,514) }\end{array}$ & $\%$ & $95 \% \mathrm{Cl}$ \\
\hline Gender & & & \\
Male & 1,164 & 48.74 & $(46.85-50.62)$ \\
Female & 1,350 & 51.26 & $(49.38-53.15)$ \\
Age & & & \\
$55-64$ & 915 & 47.34 & $(44.91-49.78)$ \\
$65-74$ & 898 & 28.40 & $(26.50-30.38)$ \\
$75+$ & 701 & 24.26 & $(22.42-26.20)$ \\
Education & 370 & 14.34 & $(12.91-15.91)$ \\
Elementary & 1,692 & 68.67 & $(66.55-70.71)$ \\
Secondary & 414 & 16.99 & $(15.30-18.83)$ \\
$\quad$ Tertiary & & & \\
Linguistic region & 1,833 & 72.71 & $(70.45-74.86)$ \\
German & 598 & 24.19 & $(22.12-26.38)$ \\
French & 83 & 3.10 & $(2.40-4.00)$ \\
Italian & & &
\end{tabular}


population. Separate multivariate logistic regressions were performed for each EOL attribute $(0=$ not important/not so important; $1=$ important/very important) to determine their association with respondents' personal characteristics and the linguistic region in which they live. Analyses were conducted using Stata SE v.14.0 software (StataCorp, College Station, TX, USA). Estimated standard errors were adjusted for potential unobserved dependencies between partners' responses. Results of the full logistic regression models are presented in Annex 2 in the Supplementary Material. The figures of the result section below present the predicted margins (i.e. standardized proportions adjusting for all of the other model covariates) for a specific characteristic (e.g., gender) across the 23 multivariate logistic regression models. Finally, the value 1 on the outcomes corresponds to both answer categories, "important" and "very important", but we will refer to them collectively as "important" in the following paragraphs.

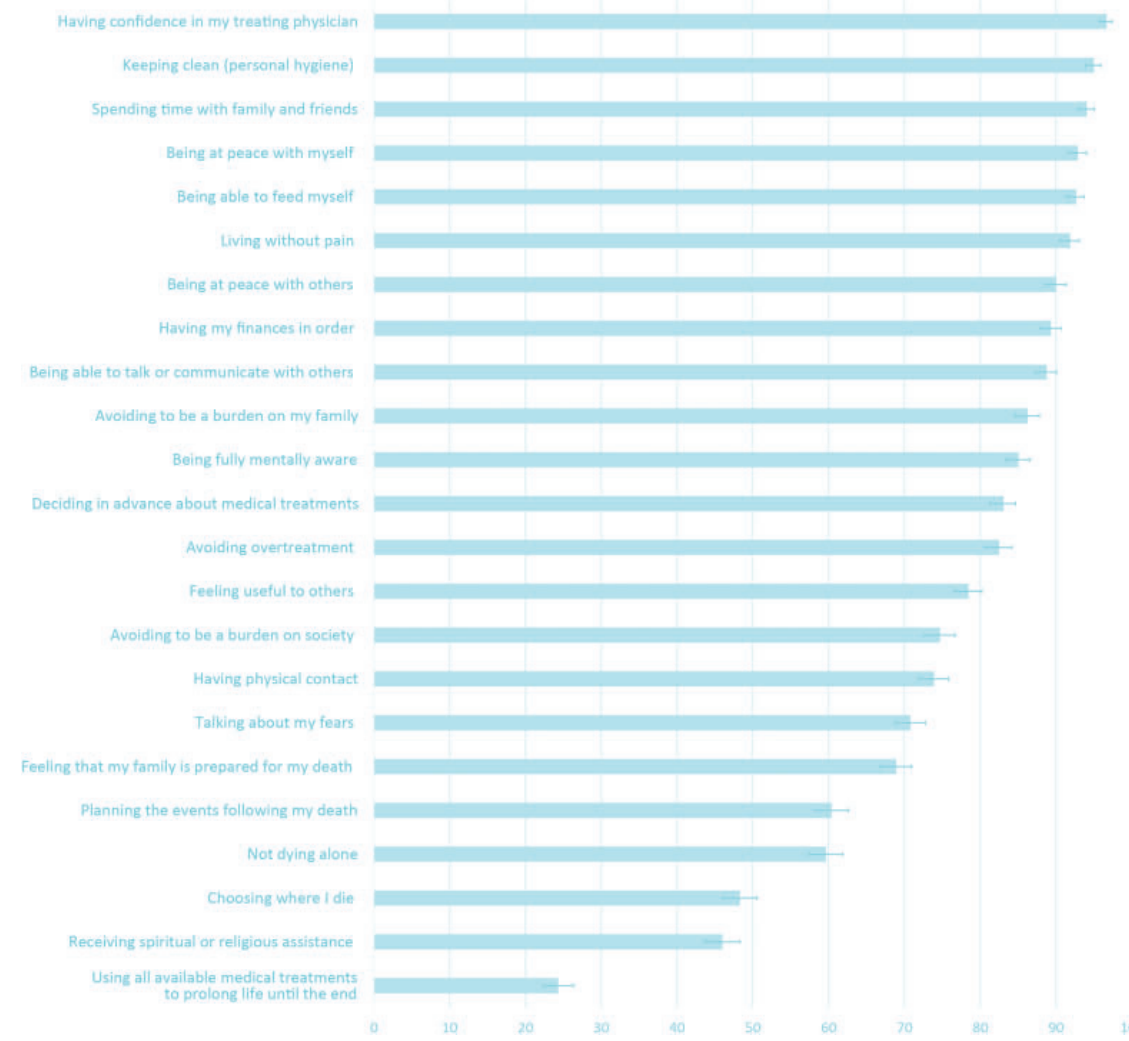

Figure I. Weighted Percentage (With $95 \% \mathrm{Cl}$ ) of Respondents Who Mentioned that the Specific EOL Attribute Was Important or Very Important $(n=2,5 \mid 4)$. 


\section{Results}

2,806 respondents participated in SHARE wave six in Switzerland and 94\% of those also completed our EOL questionnaire, resulting in a sample of 2,630 respondents. Excluding participants younger than 55 years and those with missing values on all EOL attributes, the descriptive sample includes 2,514 individuals (Table 1) and is the basis for the estimated proportions (Figure 1). For the logistic regressions, participants with missing values on the independent and control variables were further excluded, and in two logistic regressions ("having confidence in my treating physician", "keeping clean"), Italian-speaking respondents had to be excluded due to lack of variability in the dependent variable. The sample size of each logistic regression varies between 2,046 and 2,135 individuals, depending on the number of missing values for the respective EOL attribute used as outcome variable.

\section{Ranking of End-of-Life Aspects}

Figure 1 displays the weighted percentage (with 95\% CI) of respondents who considered a specific EOL attribute as "important". Of the $23 \mathrm{EOL}$ attributes considered here, the EOL attribute that most people considered as "important" is "having confidence in my treating physician" (97\%), followed by "keeping clean" $(95 \%)$, "spending time with family and friends" (94\%), "being at peace with myself" (93\%), "being able to feed myself" (93\%) and "living without pain" $(92 \%)$. By contrast, the EOL attribute that was considered "important" least frequently is "using all available medical treatments to prolong life until the end" $(24 \%)$, followed by "receiving spiritual or religious assistance" $(46 \%)$, "choosing where I die" (48\%), "not dying alone" (59\%) and "planning the events following my death" $(60 \%)$.

\section{Multivariate Analyses}

Gender: Figure 2 presents the predicted margins for gender. Gender is significantly related to many EOL attributes. The most important gender differences are related to EOL attributes that reflect psychosocial aspects of EOL. Women attach more importance to "talking about their fears" (82\% versus 64\%), "not dying alone" (71\% versus 57\%) and "having physical contact" (84\% versus $70 \%$ ). Some aspects related to EOL planning are also more frequently considered as important by women. Women attach more importance to "choosing where to die" (56\% versus $42 \%)$, "planning the events following death" $(66 \%$ versus $58 \%)$, "deciding in advance about medical treatments" $(89 \%$ versus $82 \%)$ and "feeling that the family is prepared for their death" ( $76 \%$ versus $68 \%$ ). Finally, women attach more importance to "avoiding overtreatment" $(90 \%$ versus $80 \%)$ and less importance to "using all available medical treatments to prolong life until the end" (21\% versus $28 \%)$. Further, women attach 


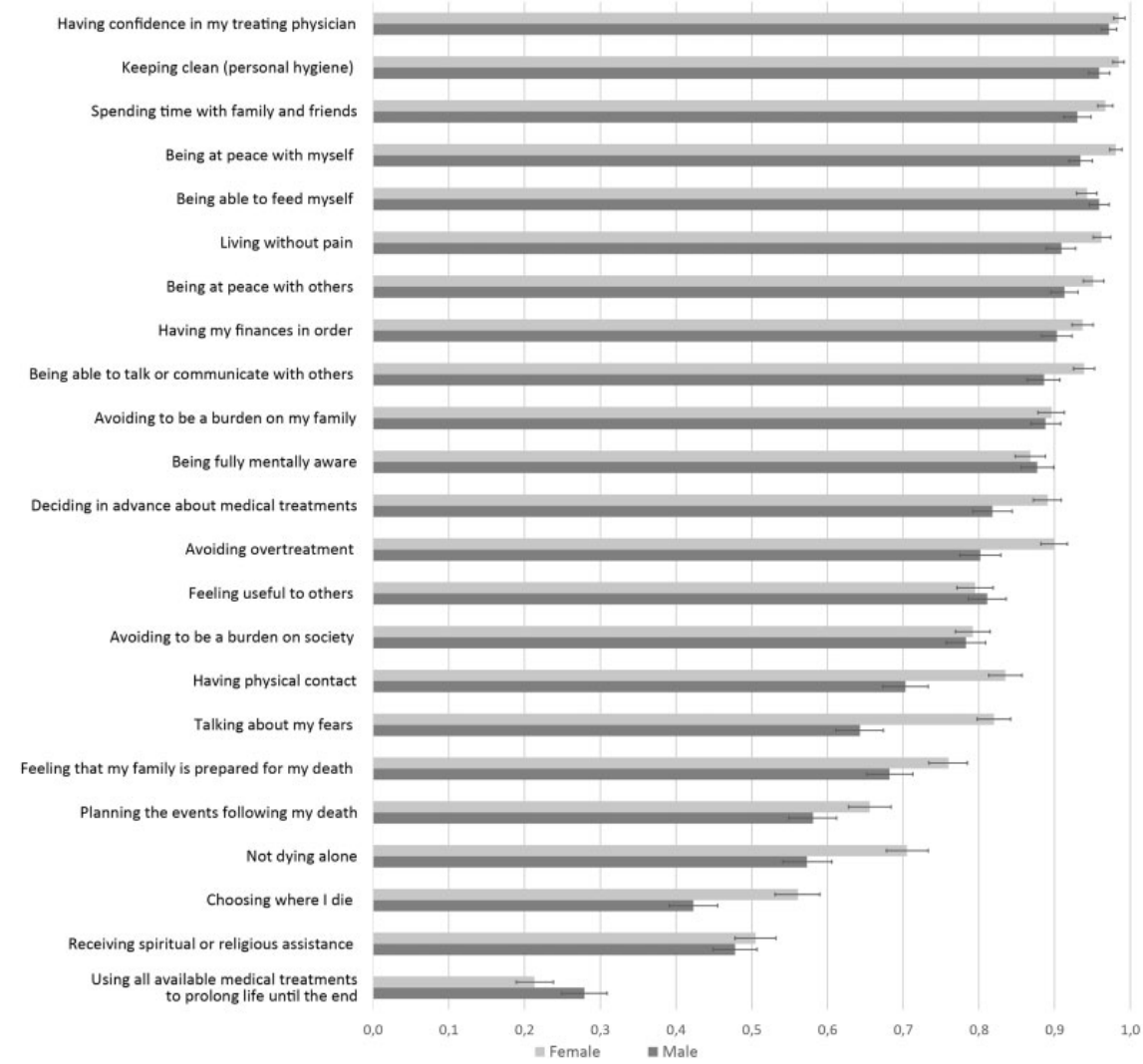

Figure 2. Percentage of Individuals, Broken by Gender, Finding the Specific EOL Attribute Important or Very Important With $95 \%$ Confidence Intervals. Predicted margins were determined using logistic regression models with age, education, linguistic region, partnership status, children, living area, financial situation, frequency of prayer, subjective health and depression as covariates.

more importance to "spending time with family and friends", "being at peace with oneself" or "with others", "being able to talk or communicate with others", "living without pain" and "having confidence in the treating physician". Although statistically significant, these differences were however relatively small in magnitude ( 5 percentage points or less).

Age: Figure 3 presents the predicted margins for age groups. Noteworthy are the age differences in the importance of EOL attributes depicting fear of becoming a burden to others. People aged $75+$ are significantly more likely than the youngest age group to attach importance to "avoiding to be a burden on society" (55-64: 70\%, 65-74: 81\%, 75+: 88\%) and "on the family" (55-64: 85\%, 


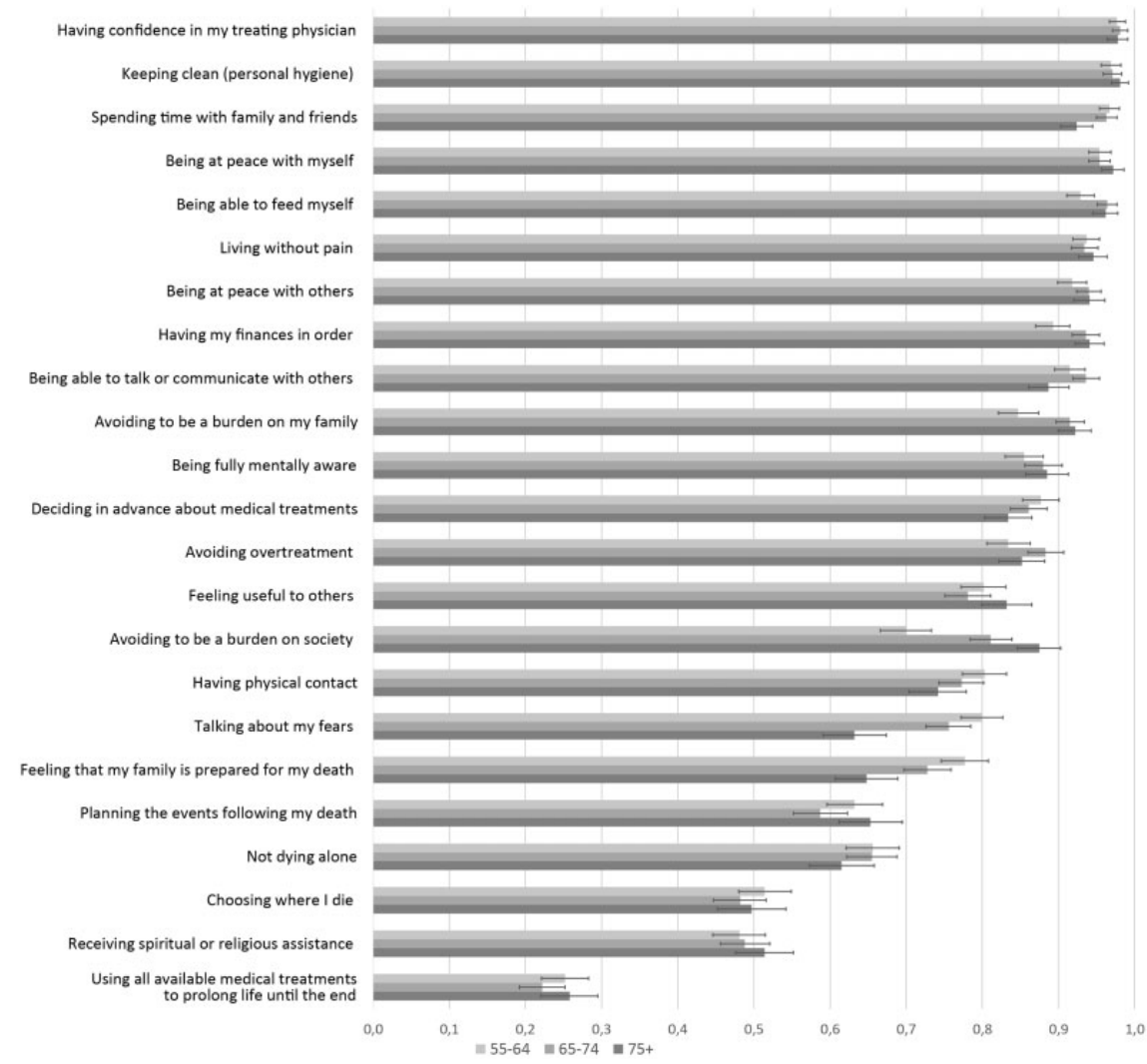

Figure 3. Percentage of Individuals, Broken by Age Groups, Finding the Specific EOL Attribute Important or Very Important With $95 \%$ Confidence Intervals. Predicted margins were determined using logistic regression models with age, education, linguistic region, partnership status, children, living area, financial situation, frequency of prayer, subjective health and depression as covariates.

65-74: 92\%, 75+: 92\%). Other important age differences concern the items "talking about my fears" (55-64: 80\%, 65-74: 76\%, 75+: 63\%) and "feeling that my family is prepared for my death" (55-64: 78\%, 65-74: 73\%, 75+: 65\%) to which older adults tend to attach less importance. Less marked, but still in the same vein, people aged $75+$ are significantly less likely than the youngest age group to attach high importance to "spending time with the family and friends" (55-64: 97\%, 65-74: 96\%, 75+: 92\%) and "having physical contact" (55-64: 80\%, 65-74: 77\%, 75+: 74\%).

Education: Figure 4 presents the predicted margins for education. The most marked education difference is related to the importance that people attach to overtreatment. Higher education levels are associated with more importance 


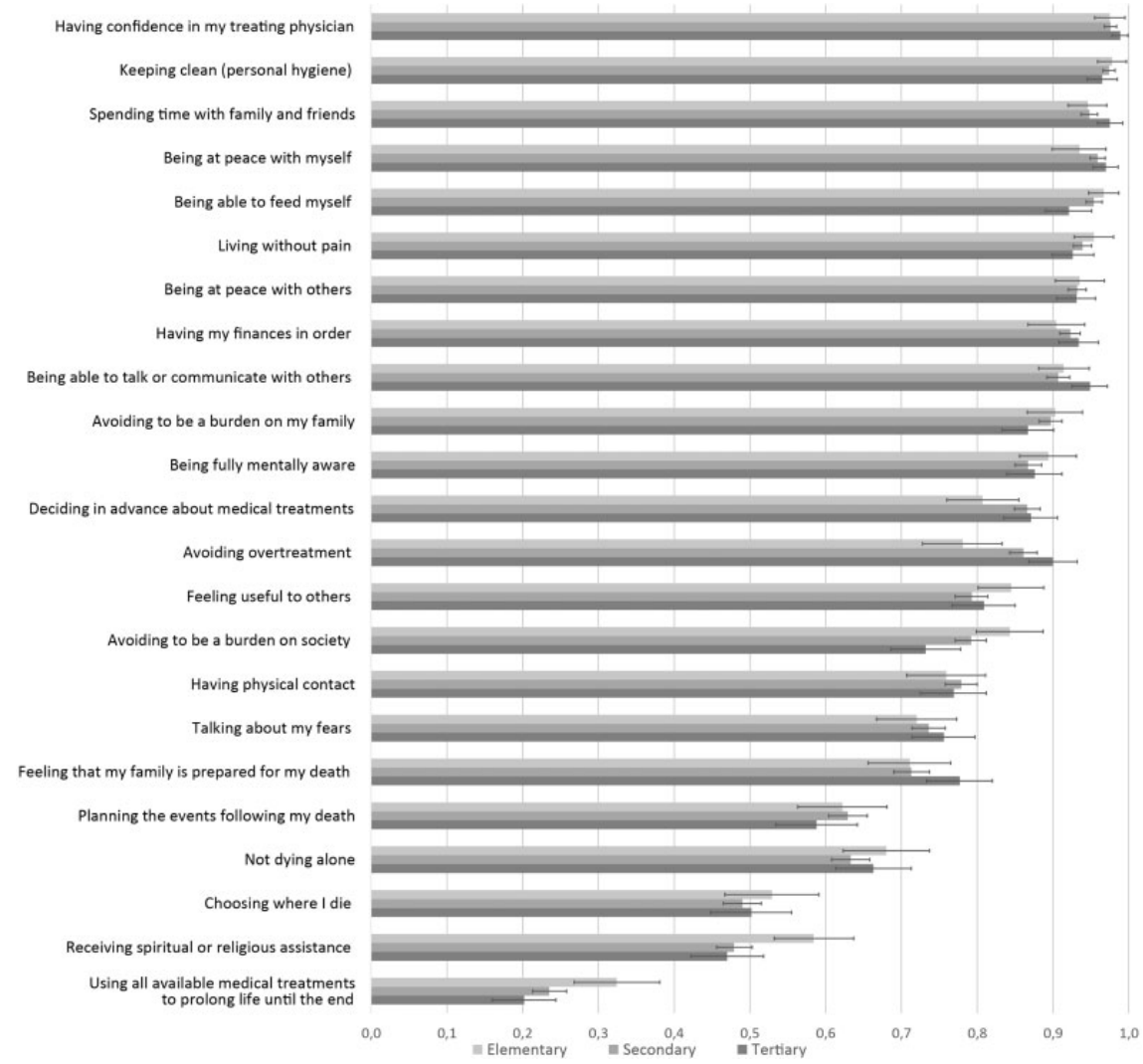

Figure 4. Percentage of Individuals, Broken by Education Levels, Finding the Specific EOL Attribute Important or Very Important With $95 \%$ Confidence Intervals. Predicted margins were determined using logistic regression models with gender, age, linguistic region, partnership status, children, living area, financial situation, frequency of prayer, subjective health and depression as covariates.

attached to "avoiding overtreatment" (elementary: $78 \%$, secondary: $86 \%$, tertiary: 90\%) and less importance attached to "using all available treatments to prolong life until the end" (elementary: 32\%, secondary: 24\%, tertiary: 20\%). Education is also related to the perceived importance of "deciding in advance about medical treatments" with respondents with completed secondary or tertiary education attaching more importance to this EOL attribute than respondents with elementary education only (elementary: $81 \%$, secondary: $87 \%$, tertiary: $87 \%$ ). Finally, education is also related to the perceived importance of "receiving spiritual or religious assistance" (elementary: 58\%, secondary: $48 \%$, tertiary: $47 \%$ ) and the importance of "avoiding to be a burden on society" (elementary: $84 \%$, secondary: $79 \%$, tertiary: $73 \%$ ). 
Linguistic regions: Figure 5 presents the predicted margins for the three linguistic regions in Switzerland, which show important differences regarding EOL planning. Swiss Germans attach more importance to "choosing where to die" (German: 56\%, French: 34\%, Italian: 24\%), "planning the events following their death" (German: 67\%, French: 48\%, Italian: 47\%) and "deciding in advance about medical treatments" (German: 88\%, French: 78\%, Italian: $91 \%$ ) compared to people living in the French-speaking region of Switzerland (results for the Italian-speaking region may not be fully representative due to the relatively small number of respondents from this linguistic region). Swiss Germans also attach relatively more importance to "talking about their fears" (German: 78\%, French: 63\%, Italian: 53\%) and "having physical contact"

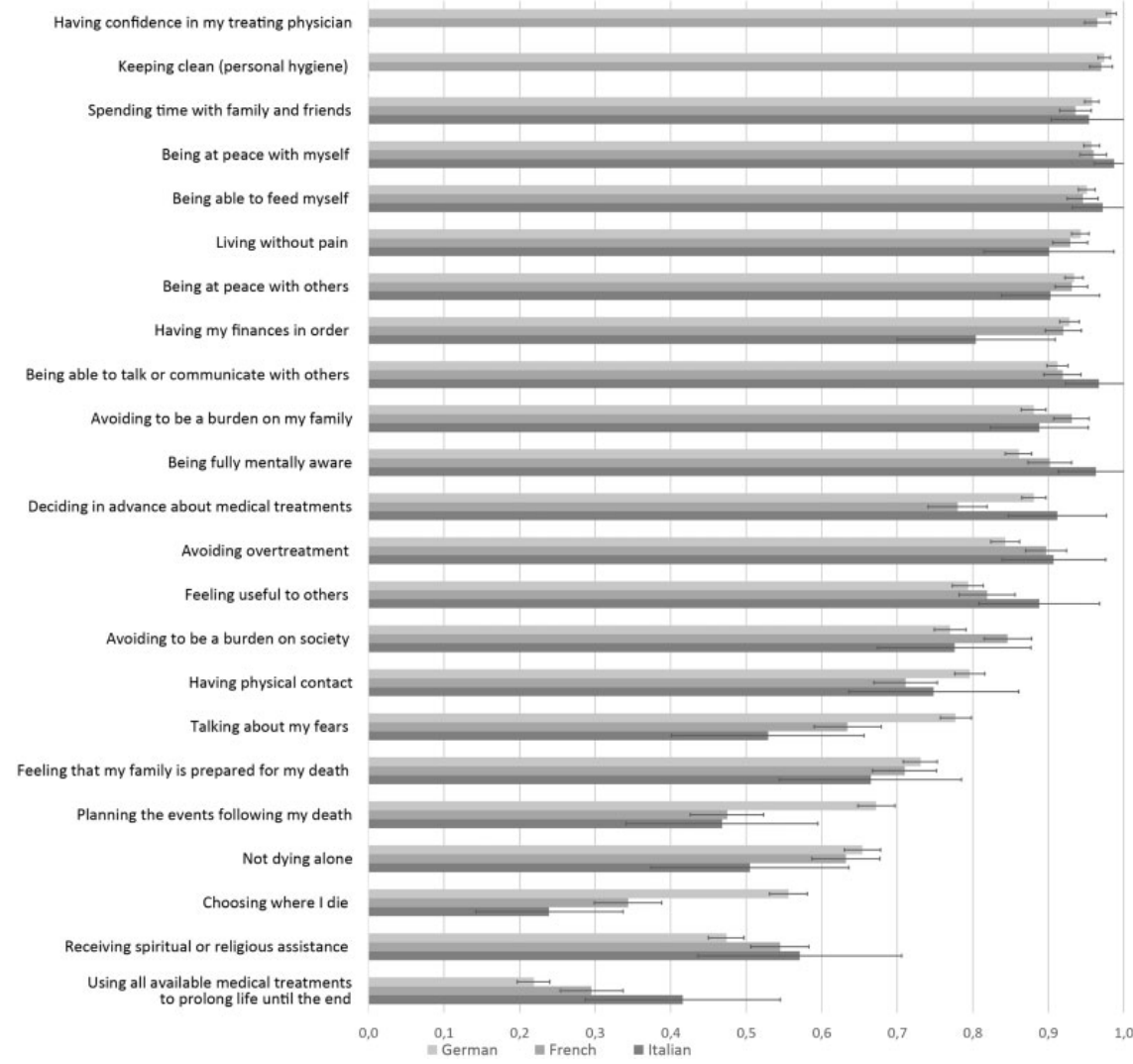

Figure 5. Percentage of Individuals, Broken by Linguistic Regions, Finding the Specific EOL Attribute Important or Very Important With $95 \%$ Confidence Intervals. Predicted margins were determined using logistic regression models with gender, age, education, partnership status, children, living area, financial situation, frequency of prayer, subjective health and depression as covariates. 
(German: 80\%, French: 71\%, Italian: 75\%). By contrast, Swiss Germans attach relatively less importance to "receiving religious or spiritual assistance" (German: 47\%, French: 55\%, Italian: 57\%) and "avoiding to be a burden on society (German: 77\%, French: 85\%, Italian: 78\%) or "on the family" (German: 88\%, French: 93\%, Italian: 89\%). Regarding potential overtreatment at the EOL, people living in the French-speaking region appear to display rather inconsistent preferences. On the one hand, French-speaking respondents attach more importance to "avoiding overtreatment" (German: 84\%, French: 90\%, Italian: 91\%) compared to Swiss Germans, but also report a relatively higher importance of "using all available treatments to prolong life until the end" (German: 22\%, French: 30\%, Italian: 42\%).

\section{Discussion}

Our results show that many of the considered EOL aspects were evaluated as "important" or "very important" by a large majority of the population. Almost everyone agreed that it is important to have confidence in one's treating physician, to keep clean, to spend time with the family or with friends, to be at peace with oneself, to be able to feed oneself and to live without pain. On the other hand, respondents were more divided about the importance of planning the events following one's death, not to die alone, to choose where to die and to receive spiritual or religious assistance. Importantly, only a minority of the respondents mentioned that they consider it important to use all available medical treatments to prolong life until the end.

Noteworthy is the high perceived importance of deciding in advance about medical treatments. This result may not be too surprising, as Switzerland is one of the countries that value autonomy and independence the most (Abrams et al., 2011) and these values appear to also extend to the EOL (Miccinesi et al., 2005; van der Heide et al., 2003). This finding is also consistent with the fact that the majority of older people in Switzerland consider advance directives favorably despite the relatively low uptake of advance directives of only $25 \%$ among the older population in Switzerland to date (Vilpert et al., 2018).

\section{End-of-Life Preferences Are Clearly Gendered}

The analyses of associations between EOL preferences and socio-demographic characteristics highlight important gender differences in EOL preferences, which are significant for almost all EOL attributes considered in our study. The use of different coping strategies may partly explain these results, as women are more likely to use emotional and social support to cope with stressful events (Matud, 2004; Ptacek et al., 1994; Rosario et al., 1988; Tamres et al., 2002). Also the fact that women have a higher life expectancy and that they are more likely to survive their partners may explain a different approach to the EOL, including 
a greater propensity to engage in EOL planning behaviors (Alano et al., 2010; Wilson et al., 2013) and a stronger opposition to overtreatment (Arber et al., 2008; Bookwala et al., 2001). And finally, women are more likely to accompany dependent and dying relatives (Colombo et al., 2011), and therefore to cumulate what Wilson et colleagues call "lived experiences" of illnesses, of death and of dying (Wilson et al., 2013). This stronger exposure to concrete EOL experiences may also contribute to shape a different vision of EOL and explain gender differences in EOL preferences (Arber et al., 2008).

\section{The Importance of Not Becoming a Burden during Old Age}

Age is also significantly related to several EOL preferences, including the importance of avoiding to be a burden to others. In line with previous studies (Gott et al., 2017; Rietjens et al., 2006; Yun et al., 2018), older respondents in our study attach more importance to avoiding to be a burden on society and on their family compared to younger age groups. On the one side, this result can stem from an age-related increase in altruistic motives (Fegg et al., 2005; McAdams et al., 1997; Pornpattananangkul et al., 2019). It can however also reflect social pressure on older adults, who are often portrayed as a burden to society in view of potential financial pressures of population ageing on social security and health care systems (Angus \& Reeve, 2006; Gorvin \& Brown, 2012; Kaeser \& Roch, 2015). Older adults' perceptions of being a burden should be closely monitored as such perceptions may impact people's psychological well-being more broadly (Gorvin \& Brown, 2012) and are related to many healthcare and EOL decisions (McPherson et al., 2007). This issue is however often underestimated by health professionals (Steinhauser et al., 2000; Yun et al., 2018).

\section{Lower Need to Talk about One's Fears at Higher Ages}

Age is also related to certain psychosocial EOL preferences. Especially the oldest group of respondents aged 75+ is standing out, as they place less importance on "talking about their fears", "having physical contact", "feeling that their family is prepared for their death" and "spending time with their family and friends". Steinhauser et al. (2000) obtained similar results with patients whose age was close to our oldest age group. These patients generally placed less importance on similar psychosocial aspects of EOL than other stakeholders (i. e. family members, physicians and other bereaved caregivers) whose age was close to our youngest age group. This age difference may be due to the fact that older respondents fear death less than younger ones. Previous studies on attitudes towards death have shown that fear of death tends to be highest among middle-aged people and decreases as people age, stabilizing at very advanced ages (Fortner \& Neimeyer, 1999). Another potential explanation of this finding 
could be cohort effects. Further studies are needed to determine the exact reasons for these age differences in psychosocial EOL preferences.

\section{Cultural Differences in End-of-Life Planning}

Comparing the three linguistic regions reveals large differences in preferences for EOL planning. Compared to people living in the French- and Italian-speaking parts of Switzerland, Swiss-Germans attach a larger importance to planning their EOL. These results are in line with previous studies showing that the SwissGermans are more aware of advance directives, more favorable to advance directives and more likely to have advance directives (Camenzind \& Petrini, 2014; Vilpert et al., 2018). Other studies have further highlighted that SwissGermans are more likely to be involved in EOL treatment decision-making (Hurst et al., 2018) and more likely to be respected in their EOL decisions (Fischer et al., 2006) than people living in the French- or the Italian-speaking region. Interestingly, the results found in Switzerland between the three linguistic regions reflect cultural differences that can be found more broadly in Europe between Germany, France and Italy in the way death and dying are approached (Vilpert et al., 2018).

\section{Education and Overtreatment}

In line with previous studies (Chambaere et al., 2013; Volandes et al., 2008; Yun et al., 2018), we found that people with secondary and tertiary education levels attach less importance to "avoiding overtreatment" compared to people with an elementary education level. Several factors may explain this difference. First, people with lower education may be less well-informed regarding overtreatment at the EOL, less aware of problems related to overtreatment at the EOL and their understanding of the concept may be more limited. Another explanation could be that individuals with lower education may generally have more limited access to all kind of goods - including health-related services - and may, therefore, be less inclined to refuse treatments that are offered to them. A third explanation could be that individuals with lower education may have different life experiences and cultural beliefs about how to approach death, attachment to life and the need to resist at the EOL. They may for instance care more about how long they will live rather than how well they will die.

\section{Positive Association between Advance Care Planning and Education}

Our results further show that people with only elementary education attach less importance to "deciding in advance about medical treatments" than people with higher education levels. This finding is consistent with previous studies showing a positive association of education with the support for and completion of advance directives (Alano et al., 2010; Camenzind \& Petrini, 2014; Vilpert et al., 2018). 
According to Chambaere et al. (2013), this result is explained by the fact that people with higher education levels feel more comfortable in interacting with highly educated physicians and discussing their proposed course of treatment. They have a range of communication skills that make them more efficient in the doctor-patient interaction and pushes physicians to adopt shared decisionmaking style ( Verlinde et al., 2012 ). Physicians and medical staff should be sensitive to this issue, noting that less educated people may require more attention or specific interventions to make sure that they can be actively involved in any medical decisions affecting their life. Otherwise, the paradigm of increasing self-determination in medical decisions risks to widen existing social inequalities in health care access and outcomes (Chambaere et al., 2013).

\section{Limitations}

Our study has several limitations. First, non-response on our preference items was generally higher among older and less educated respondents as well as - for some items - women and people from the Swiss-German region. While rates of item non-response were always below $10 \%$, these patterns may nonetheless result in some bias of our findings. Second, not all respondents may have interpreted each item in the same way, especially regarding broader items like "avoiding to be a burden on society" or "on the family". Burden could be interpreted in terms of economic, emotional, decisional, or care considerations such that some of the documented subpopulations differences may be partially explained through different interpretations of these survey items. Similarly, the need for translation may have affected the meaning of some of the survey items despite our best efforts regarding their comparability. For instance, the standard French translation for "overtreatment" ("acharnement thérapeutique") may trigger stronger negative connotations than the corresponding Swiss-German term ("Übertherapie"). Further qualitative research would be interesting to better understand the different interpretations and more broadly the cultural differences in EOL in Switzerland. Third, the cross-sectional design of our study precludes any causal inference. Fourth, this cross-sectional design also does not allow us to determine whether the documented differences between age groups reflect age-related changes in attitudes (age effects) or attitudinal differences across generations (cohort effects). Longitudinal studies could deliver additional insights on this issue. Fifth, the data from the Italian-speaking part of Switzerland must be considered with caution as the number of cases is very low $(\mathrm{N}=83)$. Finally, other respondent characteristics, which were not included in our models, may also have contributed to the differences in EOL preferences noted here. 


\section{Conclusion}

Our results highlight the importance of a holistic and interdisciplinary approach to EOL care. While the management of pain and physical symptoms was considered important by a large majority of older adults, several psychosocial aspects, such as "having confidence in the treating physician", "avoiding to be a burden on society" or "on the family", "spending time with family and friends", "talking about fears" and EOL planning were also considered important.

The importance attached to different EOL aspects also varies by sociodemographic characteristics and linguistic region. We document significant differences between men and women, which highlight the importance of gender for EOL preferences and calls for greater attention to gender issues in EOL research and practice. The greater importance attached to "avoiding to be a burden on society" and "on the family" among older adults could reflect social pressures on older adults or stem from increasingly altruistic motives among older people. Future research should clarify the exact mechanisms at play, which may have very different implications for EOL policy. Finally, our results pointed toward cultural and social differences, particularly in terms of the importance given to EOL planning. These differences suggest that not all cultural and social groups may be equally open to or ready for increasing calls for self-determination at the EOL as frequently advocated in recent years.

\section{Acknowledgments}

This paper benefited from comments by Dr. Simon Seiler.

\section{Author Contributions}

C. B. B. conceptualized the study, analyzed and interpreted the data and drafted the manuscript. S. V. designed and developed the paper-and-pencil questionnaire on which the current study is based. All authors contributed to the development of the paper-andpencil questionnaire. All authors contributed to the conceptualization of the study and the interpretation of the data. All authors provided comments on earlier versions of the manuscript. All authors read and approved the final manuscript.

\section{Declaration of Conflicting Interests}

The author(s) declared no potential conflicts of interest with respect to the research, authorship, and/or publication of this article.

\section{Funding}

The author(s) disclosed receipt of the following financial support for the research, authorship, and/or publication of this article: This paper uses data from SHARE Wave 5 and Wave 6 release 6.1.1, as of June 19, 2018 (DOI: 10.6103/SHARE.w5.611 and 10.6103/ SHARE.w6.611) see Börsch-Supan et al. (2013) for methodological details. The SHARE 
data collection has been primarily funded by the European Commission through the 5th Framework Programme (QLK6-CT-2001-00360), through the 6th Framework Programme (SHARE-I3: RII-CT-2006-062193; COMPARE: CIT5-CT-2005-028857; and SHARELIFE: CIT4-CT-2006-028812) and through the 7th Framework Programme (SHARE-PREP: N²11909; SHARE-LEAP: N²27822; and SHARE M4: $\mathrm{N}^{\circ}$ 261982). Additional funding from the German Ministry of Education and Research, the Max Planck Society for the Advancement of Science, the U.S. National Institute on

Aging (U01_AG09740-13S2, P01_AG005842, P01_AG08291, P30_AG12815, R21_AG025169, Y1-AG-4553-01, IAG_BSR06-11, OGHA_04-064, HHSN27120130 0071C) and from various national funding sources is gratefully acknowledged (see www.share-project.org). We gratefully acknowledge financial support from the Swiss National Science Foundation (10FI14_150997/1).

\section{ORCID iD}

Carmen Borrat-Besson (D) https://orcid.org/0000-0002-8088-2810

\section{Supplemental Material}

Supplemental material for this article is available online.

\section{References}

Abrams, D., Vauclair, M., \& Swift, H. (2011). Predictors of attitudes to age across Europe. Department of Work and Pensions, Research Report No. 735, 100.

Alano, G. J., Pekmezaris, R., Tai, J. Y., Hussain, M. J., Jeune, J., Louis, B., El-Kass, G., Ashraf, M. S., Reddy, R., Lesser, M., \& Wolf-Klein, G. P. (2010). Factors influencing older adults to complete advance directives. Palliative and Supportive Care, 8(3), 267-275. https://doi.org/10.1017/S1478951510000064

Angus, J., \& Reeve, P. (2006). Ageism: A threat to "aging well" in the 21 st century. Journal of Applied Gerontology, 25(2), 137-152. https://doi.org/10.1177/0733464805285745

Arber, S., Vandrevala, T., Daly, T., \& Hampson, S. (2008). Understanding gender differences in older people's attitudes towards life-prolonging medical technologies. Journal of Aging Studies, 22(4), 366-375. https://doi.org/10.1016/j.jaging.2008.05.009

Bookwala, J., Coppola, K. M., Fagerlin, A., Ditto, P. H., Danks, J. H., \& Smucker, W. D. (2001). Gender differences in older adults' preferences for life-sustaining medical treatments and end-of-life values. Death Studies, 25(2), 127-149. https://doi.org/ $10.1080 / 07481180126202$

Borreani, C., \& Miccinesi, G. (2008). End of life care preferences. Current Opinion in Supportive and Palliative Care, 2(1), 54-59. https://doi.org/10.1097/spc. 0b013e3282f4cb27

Börsch-Supan, A., Brandt, M., Hunkler, C., Kneip, T., Korbmacher, J., Malter, F., Schaan, B., Stuck, S., \& Zuber, S., SHARE Central Coordination Team. (2013). Data resource profile: The survey of health, ageing and retirement in Europe (SHARE). International Journal of Epidemiology, 42(4), 992-1001. https://doi.org/ $10.1093 / \mathrm{ije} / \mathrm{dyt} 088$ 
Camenzind, P., \& Petrini, L. (2014). Personen ab 55 jahren im gesundheitssystem: Schweiz und internationaler vergleich 2014 [People aged 55 and over in the healthcare system: Switzerland and international comparison 2014]. Obsan Dossier, 43.

Carr, D. (2012). The social stratification of older adults' preparations for end-of-Life health care. Journal of Health and Social Behavior, 53(3), 297-312. https://doi.org/10. $1177 / 0022146512455427$

Carr, D., \& Khodyakov, D. (2007). End-of-life health care planning among young-old adults: An assessment of psychosocial influences. The Journals of Gerontology. Series B, Psychological Sciences and Social Sciences, 62(2), S135-S141. https://doi.org/10. $1093 /$ geronb/62.2.s135

Castra, M. (2003). 1. Les transformations sociales du mourir [1. The social transformations of the dying]. Le Lien Social, 21-55.

Chambaere, K., Rietjens, J. A. C., Cohen, J., Pardon, K., Deschepper, R., Pasman, H. R. W., \& Deliens, L. (2013). Is educational attainment related to end-of-life decision-making? A large post-mortem survey in Belgium. BMC Public Health, 13(1), 1055. https://doi.org/10.1186/1471-2458-13-1055

Colombo, F., Llena-Nozal, A., Mercier, J., \& Tjadens, F. (2011). Help wanted? Providing and paying for long-term care, OECD Health Policy Studies, OECD Publishing, Paris.

Fegg, M. J., Wasner, M., Neudert, C., \& Borasio, G. D. (2005). Personal values and individual quality of life in palliative care patients. Journal of Pain and Symptom Management, 30(2), 154-159. https://doi.org/10.1016/j.jpainsymman.2005.02.012

Fischer, S., Bosshard, G., Faisst, K., Tschopp, A., Fischer, J., Bär, W., \& Gutzwiller, F. (2006). Swiss doctors' attitudes towards end-of-life decisions and their determinants: A comparison of three language regions. Swiss Medical Weekly, 136(23-24), 370-376. https://doi.org/10.5167/uzh-18424

Fortner, B. V., \& Neimeyer, R. A. (1999). Death anxiety in older adults: A quantitative review. Death Studies, 23(5), 387-411. https://doi.org/10.1080/074811899200920

Gorvin, L., \& Brown, D. (2012). The psychology of feeling like a burden: A review of the literature. Social Psychology Review, 14(1), 28-41.

Gott, M., Frey, R., Wiles, J., Rolleston, A., Teh, R., Moeke-Maxwell, T., \& Kerse, N. (2017). End of life care preferences among people of advanced age: LiLACS NZ. BMC Palliative Care, 16(1), 10. https://doi.org/10.1186/s12904-017-0258-0

Heyland, D. K., Dodek, P., Rocker, G., Groll, D., Gafni, A., Pichora, D., Shortt, S., Tranmer, J., Lazar, N., Kutsogiannis, J., Lam, M., \& Canadian Researchers End-ofLife Network (CARENET). (2006). What matters most in end-of-life care: Perceptions of seriously ill patients and their family members. Canadian Medical Association Journal, 174(5), 627-633. https://doi.org/10.1503/cmaj.050626

Hirai, K., Miyashita, M., Morita, T., Sanjo, M., \& Uchitomi, Y. (2006). Good death in Japanese cancer care: A qualitative study. Journal of Pain and Symptom Management, 31(2), 140-147. https://doi.org/10.1016/j.jpainsymman.2005.06.012

Hurst, S. A., Zellweger, U., Bosshard, G., Bopp, M., \& Swiss Medical End-of-Life Decisions Study Group. (2018). Medical end-of-life practices in Swiss cultural regions: A death certificate study. BMC Medicine, 16(1), 54. https://doi.org/10.1186/s12916-018-1043-5

Kaeser, L., \& Roch, P.-A. (2015). Le vieillissement actif: Élaboration, légitimation et tentatives de diffusion d'un référentiel transversal en Europe [Active aging: 
Development, legitimization and attempts to disseminate a cross-reference framework in Europe]. Critique Internationale, 68(3), 145-169. https://doi.org/10.3917/crii.068.0145

Leichtentritt, R. D., \& Rettig, K. D. (2000). The good death: Reaching an inductive understanding. Omega - Journal of Death and Dying, 41(3), 221-248. https://doi.org/ 10.2190/2glb-5ykf-4162-djud

Malter, F., \& Börsch-Supan, A. (Eds.). (2017). SHARE wave 6: Panel innovations and collecting dried blood spots. Munich Center for the Economics of Aging.

Matud, M. P. (2004). Gender differences in stress and coping styles. Personality and Individual Differences, 37(7), 1401-1415.

McAdams, D. P., Diamond, A., de St Aubin, E., \& Mansfield, E. (1997). Stories of commitment: The psychosocial construction of generative lives. Journal of Personality and Social Psychology, 72(3), 678-694. https://doi.org/10.1037//0022-3514.72.3.678

McPherson, C. J., Wilson, K. G., \& Murray, M. A. (2007). Feeling like a burden to others: A systematic review focusing on the end of life. Palliative Medicine, 21(2), 115-128. https://doi.org/10.1177/0269216307076345

Meier, E. A., Gallegos, J. V., Thomas, L. P., Depp, C. A., Irwin, S. A., \& Jeste, D. V. (2016). Defining a good death (successful dying): Literature review and a call for research and public dialogue. The American Journal of Geriatric Psychiatry, 24(4), 261-271. https://doi.org/10.1016/j.jagp.2016.01.135

Miccinesi, G., Fischer, S., Paci, E., Onwuteaka-Philipsen, B. D., Cartwright, C., van der Heide, A., Nilstun, T., Norup, M., \& Mortier, F., \& EURELD Consortium. (2005). Physicians' attitudes towards end-of-life decisions: A comparison between seven countries. Social Science \& Medicine, 60(9), 1961-1974. https://doi.org/10.1016/j.socs cimed.2004.08.061

Miyashita, M., Sanjo, M., Morita, T., Hirai, K., \& Uchitomi, Y. (2007). Good death in cancer care: A nationwide quantitative study. Annals of Oncology, 18(6), 1090-1097. https://doi.org/10.1093/annonc/mdm068

Payne, S. A., Langley-Evans, A., \& Hillier, R. (1996). Perceptions of a 'good' death: A comparative study of the views of hospice staff and patients. Palliative Medicine, 10(4), 307-312. https://doi.org/10.1177/026921639601000406

Pierson, C. M., Curtis, J. R., \& Patrick, D. L. (2002). A good death: A qualitative study of patients with advanced AIDS. AIDS Care, 14(5), 587-598. https://doi.org/10.1080/ 0954012021000005416

Pornpattananangkul, N., Chowdhury, A., Feng, L., \& Yu, R. (2019). Social discounting in the elderly: Senior citizens are good samaritans to strangers. The Journals of Gerontology. Series B, 74(1), 52-58. https://doi.org/10.1093/geronb/gbx040

Prince, M. J., Reischies, F., Beekman, A. T., Fuhrer, R., Jonker, C., Kivela, S. L., Lawlor, B. A., Lobo, A., Magnusson, H., Fichter, M., van Oyen, H., Roelands, M., Skoog, I., Turrina, C., \& Copeland, J. R. (1999). Development of the EURO-D scale-a European union initiative to compare symptoms of depression in 14 European centres. The British Journal of Psychiatry, 174(4), 330-338. https://doi.org/10.1192/bjp.174.4.330

Ptacek, J. T., Smith, R. E., \& Dodge, K. L. (1994). Gender differences in coping with stress: When stressor and appraisals do not differ. Personality and Social Psychology Bulletin, 20(4), 421-430. https://doi.org/10.1177/0146167294204009

Rainsford, S., MacLeod, R. D., Glasgow, N. J., Wilson, D. M., Phillips, C. B., \& Wiles, R. B. (2018). Rural residents' perspectives on the rural 'good death': A scoping review. 
Health \& Social Care in the Community, 26(3), 273-294. https://doi.org/10.1111/hsc. 12385

Rietjens, J. A., van der Heide, A., Onwuteaka-Philipsen, B. D., van der Maas, P. J., \& van der Wal, G. (2006). Preferences of the Dutch general public for a good death and associations with attitudes towards end-of-life decision-making. Palliative Medicine, 20(7), 685-692. https://doi.org/10.1177/0269216306070241

Rosario, M., Shinn, M., Mørch, H., \& Huckabee, C. B. (1988). Gender differences in coping and social supports: Testing socialization and role constraint theories. Journal of Community Psychology, 16(1), 55-69. https://doi.org/10.1002/1520-6629(198801) 16:1\%3C55::aid-jcop2290160108\%3E3.0.co;2-u

Singer, P. A., Martin, D. K., \& Kelner, M. (1999). Quality end-of-life care: Patients' perspectives. JAMA, 281(2), 163-168. https://doi.org/10.1001/jama.281.2.163

Steinhauser, K. E., Christakis, N. A., Clipp, E. C., McNeilly, M., McIntyre, L., \& Tulsky, J. A. (2000). Factors considered important at the end of life by patients, family, physicians, and other care providers. JAMA, 284(19), 2476-2482. https:// doi.org/10.1001/jama.284.19.2476

Tamres, L. K., Janicki, D., \& Helgeson, V. S. (2002). Sex differences in coping behavior: A meta-analytic review and an examination of relative coping. Personality and Social Psychology Review, 6(1), 2-30. https://doi.org/10.1207/s15327957pspr0601_1

Tong, E., McGraw, S. A., Dobihal, E., Baggish, R., Cherlin, E., \& Bradley, E. H. (2003). What is a good death? Minority and non-minority perspectives. Journal of Palliative Care, 19(3), 168-175. https://doi.org/10.1177/082585970301900304

van der Heide, A., Deliens, L., Faisst, K., Nilstun, T., Norup, M., Paci, E., van der Wal, G., \& van der Maas, P. J. (2003). End-of-life decision-making in six European countries: Descriptive study. The Lancet, 362(9381), 345-350. https://doi.org/10.1016/ s0140-6736(03)14019-6

Verlinde, E., De Laender, N., De Maesschalck, S., Deveugele, M., \& Willems, S. (2012). The social gradient in doctor-patient communication. International Journal for Equity in Health, 11(1), 12. https://doi.org/10.1186/1475-9276-11-12

Vig, E. K., Davenport, N. A., \& Pearlman, R. A. (2002). Good deaths, bad deaths, and preferences for the end of life: A qualitative study of geriatric outpatients. Journal of the American Geriatrics Society, 50(9), 1541-1548. https://doi.org/10.1046/j.15325415.2002.50410.x

Vig, E. K., \& Pearlman, R. A. (2004). Good and bad dying from the perspective of terminally ill men. Archives of Internal Medicine, 164(9), 977-981. https:/doi.org/ 10.1001/archinte.164.9.977

Vilpert, S., Borrat-Besson, C., Maurer, J., \& Borasio, G. D. (2018). Awareness, approval and completion of advance directives in older adults in Switzerland. Swiss Medical Weekly, 148, w14642. https://doi.org/10.4414/smw.2018.14642

Volandes, A. E., Paasche-Orlow, M., Gillick, M. R., Cook, E., Shaykevich, S., Abbo, E. D., \& Lehmann, L. (2008). Health literacy not race predicts end-of-life care preferences. Journal of Palliative Medicine, 11(5), 754-762. https://doi.org/10.1089/jpm.2007.0224

Wilson, D. M., Fillion, L., Thomas, R., Justice, C., Bhardwaj, P. P., \& Veillette, A.-M. (2009). The "good" rural death: A report of an ethnographic study in Alberta, Canada. Journal of Palliative Care, 25(1), 21-29. https://doi.org/10.1177/ 082585970902500103 
Wilson, D. M., Houttekier, D., Kunju, S. A., Birch, S., Cohen, J., MacLeod, R., \& Hewitt, J. A. (2013). A population-based study on advance directive completion and completion intention among citizens of the Western Canadian province of Alberta. Journal of Palliative Care, 29(1), 5-12. https://doi.org/10.1177/ 082585971302900102

Yun, Y. H., Kim, K.-N., Sim, J.-A., Kang, E., Lee, J., Choo, J., Yoo, S. H., Kim, M., Kim, Y. A., Kang, B. D., Shim, H.-J., Song, E.-K., Kang, J. H., Kwon, J. H., Lee, J. L., Lee, S. N., Maeng, C. H., Kang, E. J., Do, Y. R., Choi, Y. S., \& Jung, K. H. (2018). Priorities of a "good death" according to cancer patients, their family caregivers, physicians, and the general population: A nationwide survey. Supportive Care in Cancer, 26(10), 3479-3488. https://doi.org/10.1007/s00520-018-4209-y

\section{Author Biographies}

Carmen Borrat-Besson, $\mathrm{PhD}$, is senior researcher at the Centre of Expertise in the Social Sciences (FORS) and country operator of the Survey of Health, Ageing and Retirement in Europe (SHARE) for Switzerland. Her research activities focus on frailty, subjective wellbeing, end-of-life preferences and end-of-life planning in older adults.

Sarah Vilpert is a doctoral student in public health at the University of Lausanne. She is also country operator of the Survey of Health, Ageing and Retirement in Europe (SHARE) for Switzerland. Her current research interests lie in the areas of end-of-life care and planning in older adults.

Gian Domenico Borasio, MD, neurologist and palliative care physician, is professor and chair in Palliative Medicine at the University of Lausanne, Switzerland. He was a co-founder of the Interdisciplinary Center for Palliative Medicine at the University of Munich, where he held the Chair in Palliative Medicine from 2006-2011. His research interests include: meaning in life, spirituality and quality of life in palliative care, advance directives and end-of-life decisions, palliative care in neurological disorders, health services research in palliative care, and pediatric palliative care.

Jürgen Maurer, $\mathrm{PhD}$, is professor of health economics and management at the Faculty of Business and Economics at the University of Lausanne. He also serves as principal investigator and country team leader of the Survey of Health, Ageing and Retirement in Europe (SHARE) in Switzerland and has published widely in international peer-reviewed journals in the areas of health economics, health services research, demography, ageing and public health. 